\title{
ऊँ उच्चारण एवं नाड़ीशोधन प्राणायाम का विद्यार्थियों के मानसिक स्वास्थ्य पर प्रभाव का अध्ययन
}

गायत्री गुर्वेन्द्र एवं अमृत गुर्वेन्द्र

सारांश

प्रस्तुत शोध का मुख्य उद्देश्य ऊँ उच्चारण एवं नाड़ीशोधन प्राणायाम का विद्यार्थियों के मानसिक स्वास्थ्य पर पड़ने वाले प्रभाव का अध्ययन है। इस अध्ययन में प्रयोगात्मक एवं नियंत्रित समूह अभिकल्प का प्रयोग किया गया। क्रमबद्ध प्रतिचयन विधि द्वारा गायत्री विद्यामंदिर, नीमच (म. प्र.) से 11 से 15 वर्ष की आयु के 60 विद्यार्थियों का चयन किया गया। जिनमें 30 विद्यार्थियों को प्रयोगात्मक समूह तथा 30 विद्यार्थियों को नियंत्रित समूह में रखा गया। आंकड़ों के संग्रहण मानसिक स्वास्थ्य मापनी द्वारा किया गया। प्रयोगात्मक समूह को एक माह तक प्रतिदिन सुबह 30 मिनट ऊँ उच्चारण एवं नाड़ीशोधन प्राणायाम का अभ्यास कराया गया। सांख्यिकीय विश्लेषण हेतु 'टी-परीक्षण' का प्रयोग किया गया। अध्ययन से प्राप्त परिणामों में यह पाया गया कि ऊँ उच्चारण एवं नाड़ीशोधन प्राणायाम के अभ्यास का विद्यार्थियों के मानसिक स्वास्थ्य पर सकारात्मक प्रभाव पड़ता है।

कूट शब्द : ऊँ उच्चारण, नाड़ीशोधन प्राणायाम एवं मानसिक स्वास्थ्य।

वर्तमान समय में बढ़ती हुई आधुनिकता तथा उद्योगीकरण ने जहाँ एक तरफ संसार में अभूतपूर्व वैभव तथा सुख प्रदान किया है, वहीं मानव जीवन में चिन्ताजनक अशान्ति एवं मानसिक तनाव भी उत्पन्न किया है। जिसके कारण नाना प्रकार के शारीरिक व मानसिक रोग बढ़ रहे है (सिंह, 1999)। सूचना तकनीक, संचार क्रांति और यांत्रिकता ने मानवीय जीवन में साधन-सुविधाओं की भरमार करने के साथ शारिरिक, मानसिक स्वास्थ्य में अनेकों संकट भी खडे किये हैं। जिसके कारण आज मनुष्य का जीवन अपेक्षाकृत अधिक तनावग्रस्त एवं विषादपूर्ण हुआ हैं (Agrawal, 2001)।

आधुनिक कही जाने वाली अस्त-व्यस्त जीवन शैली व बिगड़े हुए खान-पान और सफलता की अंधी दौड़ में उच्चतर जीवन मूल्यों की उपेक्षा से आंतरिक विक्षोभ बढ़ा है और विकास की प्रक्रिया अवरूद्ध हुई है। जिनके परिणामों से सभी अवगत है। योग ही वह माध्यम है जो मानवीय चेतना की अन्तर्शक्तियों को जागृत एवं सुविकसित करता है। 'योग' शब्द का अर्थ है 'सम्मिलित होना अथवा एक होना' है। इस एकीकरण का अर्थ जीवात्मा तथा परमात्मा का एकीकरण है अथवा मनुष्य के व्यक्तित्व के शारीरिक, मानसिक, बौद्धिक तथा आध्यात्मिक पक्षों के एकीकरण से हैं (वर्णवाल, 2002)।

योग जड़ तत्व से प्राण और फिर प्राण से मन और मन से परे विज्ञान तत्पश्चात् पूर्ण ब्रह्म की अभिव्यक्ति है। यद्यपि योग साधना व्यक्तिगत है परन्तु इसका परिणाम सार्वजनिक है क्योंकि उसका उद्देश्य मनुष्य को अतिमानस अर्थात आध्यात्मिक स्तर पर ले जाना है (गोरे, 2004)। महर्षि
अरविन्द के अनुसार- योग का उद्देश्य पृथ्वी पर अतिमानसिक चेतना को उतार लाना, उसे वहीं स्थापित करना तथा अति मानसिक चेतना से व्यष्टि और समष्टि के आन्तरिक और बाह्य जीवन को व्यवस्थित करके एक नवीन सृष्टि की रचना करना है (मिश्र, 2004)।

आज की ज्वलन समस्या बढ़ते हुए शारीरिक व मानसिक रोगों की हैं। जिनका समुचित निवारण योग में निहित हैं। 'सर्वोवेदा यत्पदं आमनन्ति" अर्थात् वह अवस्था जिसका बखान सारे वेद करते हैं। यही ऊँ सारे वेदों का केन्द्र है। ऊँ उच्चारण के निरन्तर प्रवाह से मस्तिष्क के तंतु कम्पित होने लगते है। जिससे अर्न्तप्रज्ञा का उदय होता है तथा मन शान्त और स्थिर हो जाता है (सरस्वती, 2006)।

प्रकृति के सभी तत्वों का अस्तित्व प्राण शक्ति पर निर्भर करता है। किसी भी तत्व का अस्तित्व तभी तक रहता है जब तक उसमें प्राण रहते है। प्राण के निकल जाने पर उसका अस्तित्व भी नष्ट हो जाता है। मनुष्य का संपूर्ण जीवन और विकास भी इसी प्राण तत्व पर निर्भर करता है। प्राणायाम ही एक ऐसा सरल उपाय है जिसके माध्यम से व्यक्ति अपनी प्राण शक्ति को बढ़ा सकता है। आचार्य श्रीराम शर्मा कहते हैं कि 'जिसनें इस प्राण शक्ति को जितनी अधिक मात्रा में धारण करने, पचाने व उसे सही दिशा में प्रयुक्त करने की विद्या सीख ली, वह उतना ही मनोबल सम्पन्न, स्वस्थ और दीर्घायु होता चला जाता है' (ब्रह्मवर्चस, 1993)। इस प्रकार ऊँ उच्चारण तथा नाड़ी शोधन प्राणायाम के माध्यम से नाड़ियों की शुद्धि, प्राणों का समस्त शरीर में 
सामान्तर प्रवाह, एकाग्रता, स्नायुतंत्र की मजबूती व मन की शान्ति बढ़ती हैं।

\section{शोध विधि}

\section{प्रतिदर्श एवं प्रतिचयन}

प्रस्तुत शोध अध्ययन में क्रमबद्ध प्रतिचयन विधि द्वारा गायत्री विद्यामंदिर, नीमच (म.प्र) से 11 से 15 वर्ष की आयु के 60 विद्यार्थियों का चयन किया गया।

\section{शोध अभिकल्प}

प्रस्तुत शोध अध्ययन में प्रयोगात्मक एवं नियंत्रित समूह अभिकल्प का प्रयोग किया गया है। जिनमें 30 विद्यार्थियों को प्रयोगात्मक समूह तथा 30 विद्यार्थियों को नियंत्रित समूह में रखा गया।

\section{उपकरण}

प्रस्तुत शोध अध्ययन में मानसिक स्वास्थ्य को मापने के लिए श्रीमती कमलेश शर्मा द्वारा विकसित मानसिक स्वास्थ्य मापनी का प्रयोग किया गया।

परिणाम

सारणी (1): प्रयोगात्मक समूह एवं नियंत्रित समूह के मानसिक स्वास्थ्य स्तर के मध्य तुलना।

\begin{tabular}{|c|c|c|c|c|c|c|c|c|c|}
\hline Group & Test & $\mathbf{N}$ & $\mathbf{M}$ & SD & $S_{E D}$ & $r$ & df & $\mathbf{t}$ - value & $\begin{array}{c}\text { Level of } \\
\text { Significance }\end{array}$ \\
\hline \multirow{2}{*}{$\begin{array}{l}\text { Experimental } \\
\text { Group }\end{array}$} & Pre & 30 & 55 & 6.70 & \multirow[t]{2}{*}{2.05} & \multirow[t]{2}{*}{0.24} & \multirow[t]{2}{*}{29} & \multirow[t]{2}{*}{10.34} & \multirow[t]{2}{*}{$\mathrm{P}<0.01$} \\
\hline & Post & 30 & 76.23 & 9.03 & & & & & \\
\hline \multirow[t]{2}{*}{ Control Group } & Pre & 30 & 56.67 & 6.81 & \multirow[t]{2}{*}{1.71} & \multirow[t]{2}{*}{0.83} & \multirow[t]{2}{*}{29} & \multirow[t]{2}{*}{0.38} & \multirow[t]{2}{*}{$\mathrm{P}>0.05$} \\
\hline & Post & 30 & 57.33 & 6.46 & & & & & \\
\hline
\end{tabular}

उपरोक्त सारणी से स्पष्ट है कि नियंत्रित समूह के पूर्व एवं पश्चात परीक्षण का मध्यमान 56.67 एवं 57.33 है। जिसका मानक विचलनएवं 6.81 व 6.46 है। सहसम्बन्ध 0.83 तथा मानक त्रूटि विचलन 0.83 है। प्राप्त टी-मूल्य 0.38 है जो सांख्यकिय रूप से 0.05 स्तर पर सार्थक नहीं है। प्रयोगात्मक समूह के पूर्व एवं पश्चात परिक्षण का मध्यमान

\section{सांख्यिकीय विश्लेषण}

प्रस्तुत शोध अध्ययन में आंकड़ों के सांख्यिकीय विश्लेषण हेतु टी-परीक्षण का उपयोग किया गया।

\section{विधि}

प्रस्तुत शोध अध्ययन में ऊँ उच्चारण एवं नाड़ीशोधन प्राणायाम का विद्यार्थियों के मानसिक स्वास्थ्य पर पड़ने वाले प्रभाव को देखने के लिए क्रमबद्ध प्रतिचयन विधि द्वारा गायत्री विद्यामंदिर, नीमच (म. प्र.) से 11 से 15 वर्ष की आयु के 60 विद्यार्थियों का चयन किया गया। जिनमें 30 विद्यार्थियों को प्रयोगात्मक समूह तथा 30 विद्यार्थियों को नियंत्रित समूह में रखा गया। विद्यार्थियों के मानसिक स्वास्थ्य को मापने के लिए श्रीमती कमलेश शर्मा द्वारा विकसित मानसिक स्वास्थ्य मापनी का प्रयोग किया गया। अध्ययन प्रारम्भ करने से पहले दोनों समूहों की मानसिक स्वास्थ्य की जांच की गयी। इसके पश्चात केवल प्रयोगात्मक समूह को प्रतिदिन सुबह 10 मिनट तक ऊँ उच्चारण एवं 20 मिनट तक नाड़ी शोधन प्राणायाम का अभ्यास एक माह तक कराया गया। जबकि नियंत्रित समूह को कोई भी अभ्यास नहीं कराया गया। एक माह बाद दोनों समूहों का पुनः परीक्षण मानसिक स्वास्थ्य मापनी द्वारा किया गया। इसके पश्चात प्राप्त आंकड़ों के सांख्यिकीय विश्लेषण हेतु टी-परीक्षण का उपयोग किया गया।
55 एवं 76.23 है। जिसका मानक विचलन 6.7 एवं 9.03 है। सहसम्बन्ध 0.24 तथा मानक त्रूटि विचलन 2.05 है। प्राप्त टी-मूल्य 10.34 है जो सांख्यकीय रूप से 0.01 स्तर पर सार्थक है। प्राप्त परिणामों आधार पर यह कहा जा सकता है कि ओउम् उच्चारण एवं नाड़िशोधन प्राणायाम का मानसिक स्वास्थ्य पर सार्थक प्रभाव पड़ता है। 
गुर्वेन्द्र एवं गुर्वेन्द्र

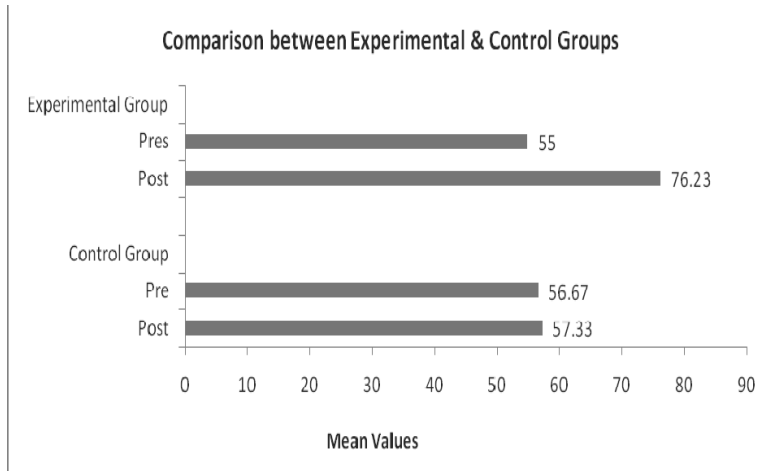

\section{विवेचना}

नाड़ी शोधन प्राणायाम में व्यक्ति श्वास प्रश्वास के माध्यम से सकारात्मक विचारों को अपने अन्दर प्रविष्ट कराता है तथा नकारात्मक भावों को बाहर निकालता है जिससे मानसिक शान्ति बढ़ती है। जबकि ऊँ उच्चारण से अर्त्तनिहित शक्तियों का जागरण होता है। ऊँ की ध्वनि से उत्पन्न होने वाले कम्पन शारीरिक व मानसिक अवस्था संतुलित होती है जिसके परिणाम स्वरूप मानसिक स्थिरता व शान्ति बढ़ती है।

ओमकार ध्वनि से प्रस्फुटित होने वाले कम्पन से एक सघन सकारात्मक उर्जा उत्पन्न होती है जो मस्तिष्क व शरीर की समस्त क्रियाओं को प्रभावित करती है। जिसके परिणाम स्वरूप व्यक्ति का पैरासिम्पेथेटिक स्नायु तंत्र सक्रिय होकर मस्तिष्क व शरीर के अन्य भागों की उत्तेजना को शान्त व संतुलित कर देता है जिसके परिणाम स्वरूप मानसिक शान्ति में वृद्धि होती है (Dave and Bhale, 1989)। स्वरूप मूर्ति (2000) ने अपने अनुसंधान के निष्कर्ष में बताया कि ऊँ उच्चारण एवं प्राणायाम से अवसाद, क्रोध, चिंता, तनाव तथा अनिद्रा रोगों से छुटकारा मिलता है तथा साथ ही साथ यह कोशिकाओं और उत्तकों की निर्माण की गति को बढ़ाता है (Murthi, 2000)। वोल्फ तथा अवेल ने अपने शोध कार्य में महामंत्र जप का तनाव, अवसाद एवं त्रिगुणों (सत्व, रजस तथा तमस) पर प्रभाव देखा। अध्ययन में पाया कि महामंत्र का जप, सावित्वक गुण बढ़ाता है, राजसिक एवं तामसिक गुणों को कम करता है तथा तनाव एवं अवसाद का दूर करता है (Wolf and Abell, 2003)।

श्रीराम शर्मा आचार्य (1998) के अनुसार मंत्र जप की दोहरी प्रतिक्रिया होती है। एक भीतर एवं दूसरी बाहर, जैसे आग जिस स्थान पर जलती है, उसे गर्म करती है एवं वायुमण्डल में भी उष्मा उत्पन्न कर अपने क्षेत्र को गर्म करती है। वैसे ही जप ध्वनि प्रवाह की भाँति अपनी हलचल उत्पन्न करता है। इन्हीं से शरीर की विभिन्न ग्रन्थियों एवं चक्रों में विशिष्ट स्तर का संचार होता है। जिससे व्यक्ति की
शारीरिक एवं मानसिक क्षमताएँ प्रभावित होती है। मानसिक तनाव मुख्य रूप से सिम्पेथेटिक तंत्रिका तंत्र को प्रभावित करता है। तनाव के दौरान संक्रिय सिम्पेथेटिक तंत्रिका तंत्र एड ${ }^{a}$ नलीन नामक स्राव तेज कर देता है। जबकि प्रणव जप के समय श्वासों की गति स्वाभाविक रूप से कम हो जाती है। जिससे सिम्पेथेटिक तंत्रिका तंत्र द्वार स्रावित एड ${ }^{a}$ नलीन हार्मोन के उत्सर्जन में कमी आती है। फलस्वरूप व्यक्ति के तनाव में कमी आती है और उसे मानसिक शांति अनुभव होती है (आचार्य, 1998)।

नाड़ी शोधन प्राणायाम, श्वास प्रश्वास के माध्यम से शरीर में प्राण प्रवाह बढ़ता है जिसके परिणाम स्वरूप मानसिक शक्ति, स्थिरता एवं शान्ति बढ़ती। प्राणायाम का सीधा सम्बन्ध हाइपोथेलेमस से है। यह हाइपोथेलेमस के माध्यम से पिट्यूटरी ग्रन्थि की क्रियाशीलता को नियमित करता है। चूँकि पिट्यूटरी ग्रन्थि अन्य सभी ग्रन्थियों का नियन्त्रक है। अतः इसके नियमित होने से सभी ग्रन्थियाँ स्वतः ही सुव्यवस्थित हो जाती हैं और इससे रोगों की उत्पत्ति की संभावनाएँ कम हो जाती हैं (नागेन्द्र, 1999)। उडूपा ने अपने एक शोध अध्ययन में यह पाया गया कि प्राणायाम के समय श्वास-प्रश्वास की गति नियमित व संतुलित हो जाती है जिसके परिणाम स्वरूप मस्तिष्क तरंगों की आवृत्ति अल्फा तरंग की ओर बढ़ती है (Udupa, 2000)। चूकि मानसिक व भावनात्मक विक्षोभ, रोग प्रतिरोधी क्षमता को प्रभावित करते है जबकि प्राणायाम के अभ्यास मस्तिष्क को विश्राम एवं शांति प्रदान करता है। क्रिसन द्वारा किये गये एक शोध अध्ययन में यह देखा गया कि प्राणायाम के द्वारा शरीर में नेचुरल किलर सेल्स की क्रिया विधि बढ़ती है जिस के परिणाम स्वरूप शरीर की प्रतिरोधी तंत्र मजबूत होता है (Crisan, 1984)। इस प्रकार स्पष्ट है कि ओउम् उच्चारण तथा प्राणायाम का अभ्यास व्यक्ति की शारीरिक व मानसिक उत्तेजना को शान्त करने के साथ इनकी क्रियाओं को संतुलित भी करता है।

\section{निष्कर्ष}

वर्तमान युग में व्यक्ति ने बाह्य प्रगति पर अपना पूर्ण ध्यान केन्द्रित किया है जिसके परिणाम स्वरूप सुख-सुविधा के साधन तो बढ़े है। किन्तु जाने-अनजाने आन्तरिक आवश्यकताओं की उपेक्षा हुई है जिसके परिणाम स्वरूप व्यक्ति नयी-नयी शारीरिक व मानसिक समस्याओं से घिरता जा रहा है। जिसका सार्थक समाधान वैदित जीवन पद्धती व योग दर्शन में निहित है। प्रस्तुत शोध अध्ययन उसी दिशा में एक छोटा प्रयास है। इस तरह शोध अध्ययन के परिणामों से 
ऊँ उच्चारण एवं नाड़ीशोधन प्राणायाम का मानसिक स्वास्थ्य पर प्रभाव का अध्ययन

स्पष्ट होता है कि ओउम् उच्चारण एवं नाड़ीशोधन प्रणायाम के नियमित अभ्यास से मानसिक स्वास्थ्य में वृद्धि होती है।

गायत्री गुर्वेन्द्र, पी-एच.डी., अमृत गुर्वेन्द, पी-एच.डी., असिसटेंट प्रोफेसर, मानव चेतना एवं योग विज्ञान विभाग, देव संस्कृति विश्वविद्यालय, हरिद्वार, उत्तराखण्ड, भारत।

\section{सन्दर्भ सूची}

आचार्य, श्रीराम शर्मा (1998). व्यक्तित्व विकास हेतु उच्चस्तरीय साधनाएँ (वाड़. मय)। मथुरा- अखण्ड ज्योति संस्थान।

गोरे, एम.एम. (2004). शरीर विज्ञान और योगाभ्यास/ पुणे; कैवल्य धाम लोनावाला

नागेन्द्र. एच. आर. (1999). प्राणायाम, कला और विज्ञान। बैंगलोरविवेकानन्द प्रकाशन।

वर्णवाल, एस. (2002). योग और मानसिक स्वास्थ्य (पृ० 34, 39)/ नई दिल्ली : न्यू भारतीय बुक कॉपारेशन।

ब्रह्मवर्चस, (1993). प्राणायाम से अधिव्याधि निवारण (पृ० 155)। मथुरा;युग निर्माण योजना।

मिश्र, डी. पी. (2004). योग और मानसिक स्वार्थ्य (पृ० 5, 10)। लखनऊ : न्यूरॉयल बुक कम्पनी।
सरस्वती, एस. एस. (2006). ध्यान योग (पृ० 68)/ उत्तरांचलः द डिवाइन लाइफ सोसायटी।

सिंह, आर. (1999). योग विज्ञान एवं यौगिक चिकित्सा (पृ० 4,5)। दिल्ली : चौखम्बा संस्कृत प्रतिष्ठान।

Agrawal, R. (2001). Stress in Life and at Work. Delhi, DL: Sage Publication.

Crisan, H. G. (1984). Pranayama in Anxiety Neurosis: A pilot study. (PhD Dissertation). Univeristy of Heidelberg, Heidelberg.

Dave, M. \& Bhale, M.V. (1989). Effect of Pranav Japa. Yoga Mimamasa, 28(1), 8-17.

Murti, S. (2000). Effect of Om chanting and Bhramari Pranayama on Mental Healh. Yoga Mimansa, 31(1), 21-35.

Udupa, K. N. (2000). Stress and its Management by Yoga. Yoga Mimansa, 22(2), 221-229.

Wolf, D. B. and Abell, N. (2003). Examining the effect of meditation techniques on psychosocial functioning. Research on Social Work Practice, 13(1), 27-42. 